\title{
COVID-19 and indigenous evaluation in Zambia: My responses to the COVID-19 pandemic
}

\section{John T. Njovu}

I started taking notice of the coronavirus outbreak when it started to quickly spread to other countries. On 13 January 2020 a first COVID-19 case outside China was confirmed in Thailand. When Europe got affected and numbers started exponentially rising in Italy and England, I became concerned.

When the World Health Organization (WHO) declared the outbreak a pandemic on 11 March and the media increased its coverage, the government started its public awareness and prevention programme. Some Zambians, including myself, volunteered to help the Ministry of Health in information dissemination. I helped translate the $\mathrm{WHO}$ guidelines into Nsenga. It is a language spoken mainly by an indigenous ethnic group, Nsenga, found in the Eastern province of Zambia.

I went into self-isolation from my community and professional circles, and got glued to my TV. I would move everywhere with a mask and also regularly test myself for any sign of the virus when I woke up in the middle of the night or morning. I would inhale 
deeply and hold my breath for some seconds before exhaling. I had read somewhere on social media that if I was unable to breathe deeply, then I had the virus. I also stopped taking any cold drinks. Any sign of a cold made me quickly take home remedies. I saw that a lot of us had been affected by the media buzz. My younger brother had to go to our local hospital several times to get checked and be reassured that he didn't have COVID-19 when he started feeling unwell. All of us in the family were biting our nails whenever he went in.

However, being an elder of my clan and neighbourhood, I found it difficult to keep away from people. Many households are being forced into poverty and to cut down on financial expenditure and daily meals. In our extended family system, the few who are able to afford it are having to bear the load for many of their relatives' households. I am one of these people. Although I am also financially constrained and adversely affected by lack of calls for consultancy, I have to help out my vulnerable extended family members, neighbours, and friends. My farm was burned in 2015 and therefore I do not have a secondary source of income that could have come in handy. There is no national unemployment benefit scheme for consultants. My recovery efforts in fish farming have been stalled by a long unpaid debt and swindle by a debt collector. I, however, still share whatever little income comes my way. I also run a youth-empowerment project in my neighbourhood. So, despite my constraints, I haven't closed my home to the neighbourhood youths who regularly turn up for mentoring or fitness workouts. Many are recently unemployed. My small effort helps in getting them off the streets and avoiding engaging in negative behaviour such as abuse of drugs or alcohol and gender-based violence. 


\section{Government's response to the pandemic}

The government issued Statutory Instrument No: 21 on 13 March 2020 to declare COVID-19 as a public-health infectious disease. It introduced measures and recommendations to prevent its spread. Zambia reported its first two COVID-19 cases on 18 March. A family who had travelled to France had tested COVID-19 positive and was quarantined. It was followed by cases of Pakistanis returning from Pakistan.

However, some members of the public did not seem to take the notice seriously. Many people have not been wearing face masks in public places and continue to gather in large numbers. Some bars continue to operate behind closed doors. The number of cases started to increase in July. Currently, we have 6,793 COVID-19 cases, 169 deaths, and 5,109 ${ }^{1}$ recoveries. Our population was estimated at 18,425,892 as of Tuesday 4 August $2020(18,383,955$ people at midyear according to United Nations data, equivalent to $0.24 \%$ of the total world population ${ }^{2}$ ).

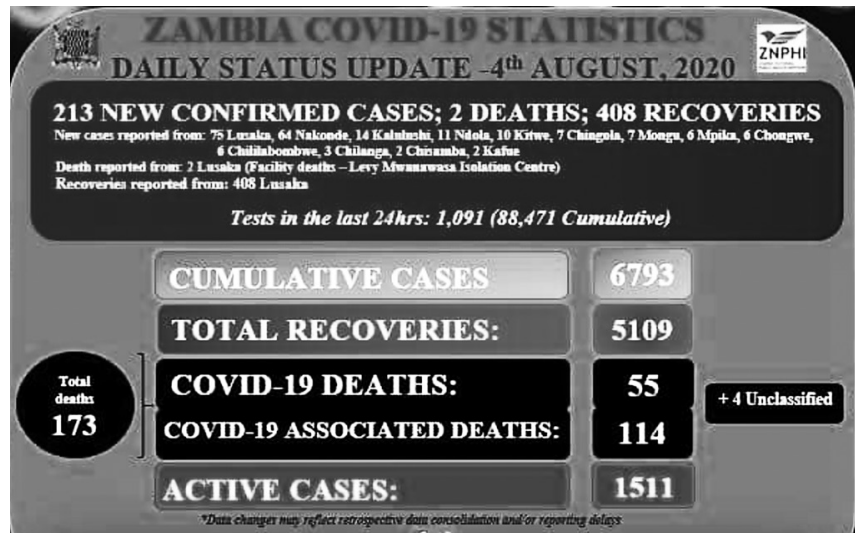

Figure 1. COVID-19 status update, 4 August 2020

1 https://www.moh.gov.zm/?fbclid=IwAR1glnh1Ad2j46mUR8MNQE17-fMV1bJvsgTDshcI5Nhf5tXA4VpyqYSCOh4

2 https://www.worldometers.info/coronavirus/country/zambia/Accessed 5 August 2020 


\section{My challenges during the pandemic}

Being an independent and indigenous evaluator, not from a leveraging technical and financial donor and government agency, in the past I used to face the following challenges in my evaluation work:

1. participants' higher expectations of a commission for taking part in a research project

2. confidentiality as an excuse for blocking my access to data by public officers

3. regular absences of the public servants to interview or clear the review notes from a commissioner

4. unreliable pledges of contact persons or key informants who would promise to do everything to help me complete my assignment and not do anything

5. censorship of reports by commissioners

6. being turned into a punch bag in a blame game for failure or the turf and power war zone of the donor funding agency or commissioner's staff and beneficiary key informants

7. crossing the many layers of royal or state establishments, security guards, and assistants to a key informant.

During this COVID-19 pandemic, my challenges include:

1. excuses by key informants for not being available owing to anxiety over the COVID-19 pandemic and adherence to social distancing

2. mistrust of communication technology and being recorded during virtual meetings by those who mistrust modern technology or do not like transparency and accountability or fear exposure of poor performance

3. lack of responses from most public institutions to queries by phone or emails 
4. inability to read the body language and decipher if someone's telling the truth while communicating orally or by SMS on a telephone or by email

5. challenges of finding suitable audio-video recording equipment for information gathering in the new normal of social distancing

6. constraints of resources to keep my office running due to the drying up of opportunities. This has led to overwork as I have to do work that usually would be undertaken by about four professional staff, three support staff, and two general workers.

Meanwhile, deadlines of the few income assignments and pro bono voluntary opportunities still have to be met. Most of my work is pro bono; for example, related to my voluntary contributions to civil society and my local and foreign professional associations. I believe in giving back to my communities, so I tend to volunteer a lot to help out.

The evaluation work plan may have only one day in the normally 22 days for the evaluation scheduled to make appointments. I also sometimes have to do favours and follow up issues on behalf of my professional friends abroad who are having communication challenges with their clients here in Zambia. However, making appointments or following up issues in Zambia is not very easy. Phones sometimes go unanswered in public offices for a long time or many days. Even when contacts promise to call me, they do not. I have to physically keep on following up. Even when I make an effort to drive to an office, I may not be given an appointment.

I sometimes find it a challenge when my ethnicity is considered by office bearers and respondents. It's getting worse now. My independence and indigenous evaluator status is sometimes doubted by the very people who may benefit from my work.

The expected hospitality of villagers is now also being affected by fear of being in contact with people from a town where there are 
reported COVID-19 cases. I am aware of this as I try to track an indigenous ethnic group that is not well known-the Batwa. (Twa is a term for one person; Batwa for people.) These are commonly referred as Bushmen and are mostly found in Botswana and South Africa in this Southern African region. We have a few of them in remote and challenging terrains of Southern and Luapula provinces. So it is not a matter of conducting an interview over a cellphone. I have to physically get to them. To avoid a hostile reception before I meet them, I have engaged a local tracker in Southern province to contact them. It would be interesting to learn how they have been integrated in the mainstream Zambian society. Of interest also is to learn whether they are aware of COVID-19 and how they are coping. This is in the spirit of not leaving anyone behind in this Sustainable Development Goals decade. It may take a bit of time and patience. However, I am hopeful that I shall eventually meet them.

I depend on assignments from the government and donor agencies. However, I sometimes embark on my own researches to help my church, civil society, or professional associations. It is not easy to get evaluation consultancies in Zambia. The culture of Monitoring and Evaluation (M\&E) in the Zambian public sector is just developing. However, funding remains a major constraint. Foreign donors of national development programmes are the main drivers of $\mathrm{M} \& \mathrm{E}$ in Zambia.

Consultancy assignments are mainly awarded to firms based in the donor community or linked to personnel in the donor agencies. A local expert may be requested to join an evaluation team headed by a foreigner but on the lowest conditions of service. The local term used is chola boy. In the colonial era, indigenous males were called boys by their European masters regardless of their age. Chola is a Bemba (one of Zambia's ethnic groups) word for a bag. Europeans in the colonial era used to move along with servants. The servant would carry the 
master's bag or umbrella. The name chola boy is for the servant who moved with the master and did nothing, not even engage in conversation, but carry simple articles for his master or mistress.

Currently, while Zambians with higher accreditations such as Master's and Doctorate degrees can be part of an international team, their conditions of service are much like those of the colonial chola boy. They usually get to be just data collectors or like interns and get paid much lower fees than their foreign counterparts.

\section{Bootleggers of evaluation}

This systematic racism in evaluation seemingly has been accepted by the local evaluators. It may be due to the difficulty of winning a major contract by locals without inside connections and to get one's hand on the much-sought-after foreign currency. In my opinion, this may be also due to evaluation experts who are carrying out evaluations on a part-time basis. These are mainly academics or civil servants with full-time formal jobs and getting sabbaticals to perform evaluations. Academics are loved by Western commissioners because of their academic rigour or rote-ness to evaluation. They, though, bring a rottenness to overall evaluation development. Staff working for commissioners of evaluations usually use proxies. They tend to look at fees from consultancies as secondary income. However, the acceptance of poor or intern's terms by highly qualified local experts has disadvantaged Africa's development of M\&E capacity. If a professor with more than 20 years' experience is accepting poor conditions, then emerging evaluators may find it very challenging to enter the profession. They also disadvantage those in the practice solely dependent on evaluation assignments. Those in the practice may have to pay for all their resources, equipment, space, and tools while academics and civil servants may use their institutions' facilities. The academics may not even give their institutions part of their consultancy income 
or pay tax on it. Therefore, many education institutions do not gain from their staff bootlegging in evaluations.

Our government contracts are dominated by those closely linked to the ruling party or public sector executives. Audits of public office do not check on relationships between service vendors and public office holders and the process of debt payments. Integrity committees at workplaces do not work as they are comprised of managers who report to the head of an institution. They do not have any independent members. Even the national plan's implementation system has the executive branch of government evaluating itself. So, for many of us evaluators who are not well connected-although we manage once in a blue moon to win contracts - it is a big challenge.

There is also a challenge of bad-debt servicing by clients. The government is notorious at taking a long time to pay debts. Therefore, some public servants have taken advantage of vendors by demanding commissions to speed up the process of payments.

\section{The house niggers of evaluation}

There is also the "house nigger" mentality among our local evaluators to blame for the continuation of systematic racism in awarding lucrative international contracts. Nigger is a negative term for a black person that has it genesis in the days of slavery in America. The house nigger is a term used for a slave who was selected to work in the house of the master but somehow forgot that he/she is still a slave. It sums up a black person's betrayal of the common causes of black people. It could be the worst insult to a fellow black person. A black person who betrays other black people is considered worse than a slave or colonial master. We still find the house nigger attitude among some African politicians, captains of industries, and professionals. Thus, nearly 54 years after political independence, Zambia is struggling with building national evaluation capacity and decolonising evaluation methodologies. 


\section{New normal in evaluation}

The new normal in evaluation and the need to adhere to social distancing call for a change in data-collection methods. This is to protect the lives of evaluators, commissioners, participants, and other stakeholders. Data collection using mobile devices needs good connectivity for the GPS mapping application to work. However, telecommunication is not usually reliable in Zambia. One needs good connectivity. Some of the applications sketch out wrong routes for enumerators. Some places are only accessible during the dry season by road. You also need a good all-terrain vehicle or aircraft if you have to reach such places. This is one of the challenges faced by beneficiaries of the cash-transfer programme (e.g., in Western province).

Another challenge is the social-distancing videography that is being requested by some commissioners. We have tended to use our personal cellphones and small cameras to record the process of our evaluations. Not all locals can afford the state-of-the-art equipment that is required for video and audio recording of a programme of a commissioner. For example, the call by the United Nations Development Programme (UNDP) for a videographer requires seemingly state-of-the-art and expensive equipment for most Zambians. There is also the challenge of hiring equipment in Zambia as it is very expensive. Most of the studios that own them are fully booked with corporate assignments most of the time. Most of the best individual videographers I know in Zambia use older equipment. Most Zambians who own cars bought them as used cars from Japan. Most of them are over 10 years old. The same for cameras in Zambia. Most local camera operators use old or budget equipment (below $\$ 3,000$ cameras). These are beginners' or budget cameras (Older Blackmagic 4K, Canon 5D and 7D, Nikon D3100, Panasonic G7, and Lumix GH4). The demand by commissioners for more than $\$ 4,000$ cameras mainly disadvantages locals. Not many can afford the latest 
high-end filming equipment. A Blackmagic design URSA Mini Pro 4.6K 62 Digital camera costs around $\$ 6,000$. A Sony PXW-FS5M2 $4 \mathrm{~K}$ XDCAM is around $\$ 5,000$. The Canon EF $24-105 \mathrm{~mm} \mathrm{f} / 4 \mathrm{~L}$ IS II USM lens is around $\$ 1,500$. Add other required audio-digital equipment and we may end up with a budget of around $\$ 10,000$ for acquiring equipment, on an expected income of $\$ 5,000$. During this period, importing equipment from China is usually at a premium. There are also some cellphones that take very high-quality videos in low light. Even if I had to acquire the equipment, the quality of taking a video depends on the type of lens, skills, and creativity of the person handling the camera. I also don't know of any good videographer here who has a Master's degree as per the United Nations Population Fund's call. ${ }^{3}$ I know of many good videographers who have very humble academic qualifications (e.g., the head of the camera's unit in one of our major national studios). Most have learnt by apprenticeship.

Another reason for this state of affairs is the weakness of national and continental M\&E associations. They, like our government, are donor dependent and seemingly cannot fight for better terms for local evaluators.

\section{Challenges of using indigenous evaluation methodologies}

The foreign donors insist on M\&E in their funded projects and programmes as they have to account to the taxpayers of their countries for the funds spent on assisting Zambia. Therefore, evaluation methodologies used in the evaluations are those promoted by the external development agencies. Although the donor community talks of culturally sensitive consideration, there is no consideration of the

3 https://unjobs.org/vacancies/1596403690606 Accessed 05 August 2020 
indigenous communities having had their own methodologies long before they were colonised or Western countries came up with their evaluation methodologies. Our government and national evaluation association do not insist on using indigenous evaluation methodologies or a mix. This could be a case of he who pays the drummer calls the tune. They are, therefore, only recognised in debates but not in practice. It is therefore challenging for an indigenous consultant to try to use indigenous evaluation methodologies or, what is commonly called here, "Made in Africa" evaluation methodologies. The African Evaluation Association has been spearheading the discussions on adopting local methodologies for a number of years now. However, as long as there is no political will by the African Union and the leaders of member states, the discussions will just remain in elitist conference centres, webinars, and professional papers.

7 August 2020 